\title{
Isolated renal hydatid disease: varied presentations, treatments, dilemmas, and the way ahead: case report series
}

\author{
Ankit Misra, Swarnendu Mandal', Manoj Das, Pritinanda Mishra, Suvradeep Mitra and Prasant Nayak
}

\begin{abstract}
Background: Hydatid disease is an infectious disease that affects several organs. Isolated renal involvement is very rare. The treatment for renal hydatid cyst ranges from minimally invasive percutaneous aspiration techniques to laparoscopic and open techniques. We describe five cases of isolated renal hydatidosis with varied presentations who were treated successfully by various methods.

Case presentation: The presenting symptoms included flank pain $(n=5)$, mass abdomen $(n=2)$, and hydaturia $(n=1)$. In 4 patients, the diagnosis of a hydatid cyst was known preoperatively, but one patient with a preoperative diagnosis of a simple cyst was found to harbor hydatidosis intra-operatively. Eosinophilia as a marker for the active disease was present in 60\% (3/5), while echinococcal serology was positive in only $25 \%$ (1/4). Two cases were approached laparoscopically, while three required an open approach. Two patients were treated with nephrectomy due to the high bulk of the disease, while the other three underwent renal preserving cyst excision.

Conclusions: The presence of eosinophilia in the preoperative workup may indicate an infective/active hydatid disease. Echinococcal serology is representative of past hydatid infection but cannot reveal about current disease status. Cysts with varied attenuations and residence in an endemic region may support a renal hydatid cyst diagnosis. A holistic approach including clinical history, laboratory parameters, and imaging is needed for diagnosis. Surgical treatment requires cyst excision, along with precautions to prevent spilling. Nephrectomy may be preferred in cases with minimal residual function.
\end{abstract}

Keywords: Echinococcosis, Renal cyst, Eosinophilia, Kidney disease

\section{Background}

Hydatid cyst commonly involves the liver in $75 \%$ and the lung in $15 \%$ of cases. Usually, renal involvement, which constitutes $2-4 \%$ of all cases, is a secondary manifestation of the disease. Isolated renal echinococcosis is even rarer [1]. Although usually diagnosed with computed tomography (CT), a hydatid cyst may sometimes present a diagnostic dilemma resembling a simple renal cyst [2]. An isolated renal hydatid cyst can also be misdiagnosed

\footnotetext{
*Correspondence: urol_swarnendu@aiimsbhubaneswar.edu.in; dr.swarnendu@gmail.com

Department of Urology, AllMS, Sijua, Dumduma, Bhubaneswar, Odisha
} 751019, India as a cystic renal neoplasm due to non-specific manifestations [3]. Isolated hydatid cysts in renal pelvis can masquerade as renal calculi [4]. Eosinophilia in the evaluation may predict the infectivity/activity of the disease [5]. Predicting the infectivity may impact the selective usage of scolicidal agents and preparations to prevent the spillage. Large or multiple renal hydatid cysts may require partial or complete resection of the kidney, depending on the residual functionality. In the present study, we describe our experience managing five isolated renal hydatidosis cases encountered in the last three years, their varied presentations, diagnostic findings, treatment, and learning regarding their management. 


\section{Case presentation}

Five patients with isolated renal hydatid disease were operated on in our department between January 2017 and February 2020. Data for this observational study were collected retrospectively from the Medical Records Department and OPD register of the institution. The presenting symptom was flank pain $(n=5)$, mass abdomen $(n=2)$, and hydaturia $(n=1)$. In 4 patients, the diagnosis of a hydatid cyst was known preoperatively, but one patient with a preoperative diagnosis of a simple cyst was found to harbor hydatidosis intra-operatively. Two cases were approached laparoscopically, while three required an open approach. Two patients were treated with nephrectomy due to the high bulk of the disease, while the other three underwent renal preserving cyst excision.

\section{Case 1}

A 26-year-old female presented with intermittent and dull aching left flank pain for one year; contrastenhanced computed tomography (CECT) revealed a simple cyst $(9.8 \mathrm{~cm} \times 8 \mathrm{~cm})$ in the left kidney (Fig. 1a-b). Eosinophilia was the only significant finding in her laboratory results. The cyst was deroofed laparoscopically with a preoperative diagnosis of a simple cyst. Clear fluid was drained, but to our surprise, a white membrane was noticed inside the cyst wall (Fig. 1c-e). No daughter cysts were found. Since we did not suspect a hydatid disease, no antiscolicidal measures were taken. There was no change in heart rate or fall in the blood pressure suggestive of intra-operative anaphylaxis. The anesthetists were informed so that they could manage the anaphylaxis, if any. The white membrane and cyst wall (Fig. 1f-g) was partly sucked out, larger pieces put in an endobag, and were sent for histopathology, which confirmed it to be a hydatid cyst. However, no anaphylactic reactions were observed in the intra-operative or postoperative period. The patient was started postoperatively on albendazole and is doing well on two years of follow-up (Table 1).

\section{Case 2}

A 40-year-old female presenting with recurrent abdominal pain for two years on ultrasound (US) revealed a large cyst $(12.2 \mathrm{~cm} \times 8.9 \mathrm{~cm})$ at the right kidney's upper pole. CECT showed a significant $(9.8 \mathrm{~cm} \times 8.5 \mathrm{~cm} \times 12.3 \mathrm{~cm})$ exophytic cystic lesion with no internal septations or calcifications. Eosinophilia was present, and echinococcal serology for IgG and IgM was negative. After deciding on a laparoscopic approach, the cystic lesion was isolated with gauze pieces soaked in povidone-iodine as a precautionary measure. After puncture and aspiration, povidone-iodine was instilled in the cavity for sterilization. After decortication, the cyst wall was sent for histopathology and showed the ectocyst and endocyst of hydatid (Fig. 1h-i).

\section{Case 3}

A 19-year-old female presenting with left flank pain for three months with no eosinophilia had a CECT showing a well-defined non-enhancing exophytic cystic lesion from the lower pole of the left kidney $(16.7 \mathrm{~cm} \times 10.7 \mathrm{~cm} \times 10.5 \mathrm{~cm})$. No internal septations were noted. Few foci of calcification were noted in the cyst wall. As the patient's serology for IgM and IgG was positive, she was started on preoperative albendazole. The patient was planned for an open approach because of the large size of the cystic lesion. Taking all precautions, aspiration and instillation of scolicidal agent were done, followed by pericystectomy. No connection was noted with the pelvicalyceal system. The histopathology confirmed it to be a hydatid cyst.

\section{Case 4}

A 53-year-old man presented with an abdominal lump for ten years, a history of passing whitish grapelike particles intermittently in the urine for five years, and a right flank pain of 5 months. The patient had a history of open exploratory laparotomy three months back for duodenal perforation. At present, he also had an incisional hernia $(6 \mathrm{~cm} \times 6 \mathrm{~cm})$ for two-month duration involving the midline incision. Eosinophilia was present, and echinococcal serology was negative.

CECT of the abdomen revealed a multicystic nonenhancing lesion with multiple internal septations $17 \times 15 \times 17 \mathrm{~cm}$ in the right kidney (Fig. 2a). There were associated areas of peripheral calcification. Cyst within cyst appearance was appreciated (Fig. 2b). The attenuation of inner cysts was lower than the outer cyst. The lesion was abutting the surrounding structures. No excretion of contrast was seen from the right kidney.

A midline incision was used to enter the abdomen. The bowel was mobilized, exposing the enlarged kidney. After taking adequate antispillage precautions (Fig. 2c), the patient underwent cyst aspiration, and around two and a half liters of putty and caseous material was aspirated (Fig. 2e), followed by injection of scolicidal solution ( $10 \%$ povidone-iodine). During nephrectomy, a part of the pericyst was found to be densely adhered to the duodenum, the inferior vena cava, and the pleura and was left as such to avoid extensive reconstructive surgery and save operative time.. Anatomical repair of the incisional hernia was done. Numerous daughter cysts were appreciated in the surgical specimen (Fig. 2d). The patient was continued on albendazole postoperatively. Histopathology came out to be hydatid as expected (Fig. $2 \mathrm{f}-\mathrm{g}$ ). 


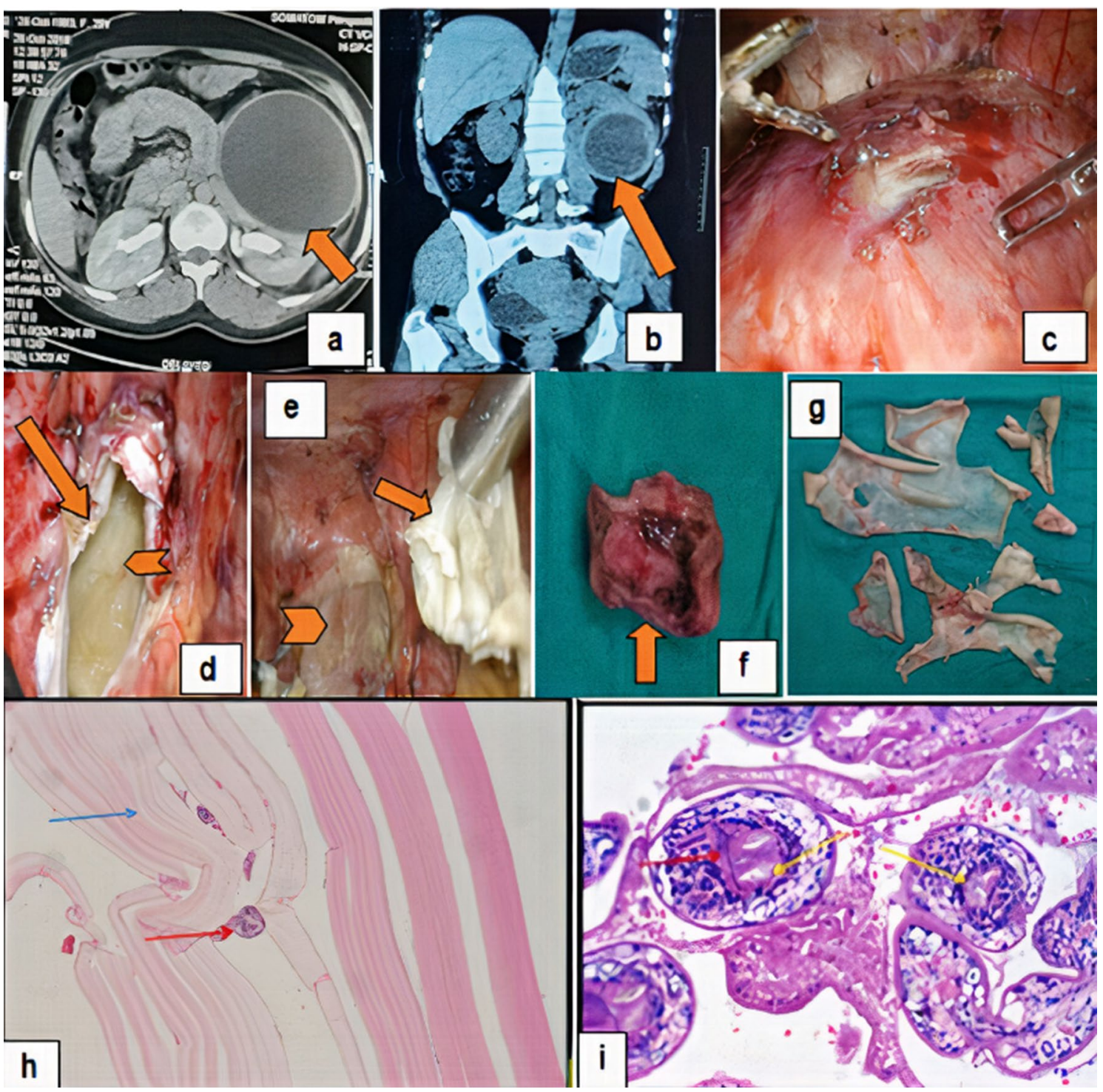

Fig. 1 a, b CT scan showing a large cystic lesion (orange arrow) in the left kidney resembling a simple cyst. c Cystic lesion of the kidney exposed after dissecting the splenocolic attachments and colon. $\mathbf{d}$ Cyst wall (orange arrow) incised and a white membrane seen inside the cyst cavity (orange arrowhead). e White membrane (orange arrow) sucked out along with clear fluid. No daughter cysts visualized in the cavity (orange arrowhead). $\mathbf{f}$ Cyst wall (orange arrow) sent for histopathology. $\mathbf{g}$ Membrane pieces sent for histopathology. $\mathbf{h}$ Acellular lamellated hyaline ectocyst (blue arrow) and a scolex (red arrow), 4X, H\&E. i Protoscolex contains sucker (red arrow) and hooklets (yellow arrow), 40X, H\&E

\section{Case 5}

A 45-year-old gentleman had a lump in the abdomen of 9-month duration with associated dull aching pain. On examination, the lump involved the left hypochondrium, left lumbar and umbilical region of the abdomen and seemed to cross the midline (Fig. 3a-b). The patient had a negative echinococcal serology, no eosinophilia, and a three-month course of albendazole. Computed tomography revealed a large cystic lesion $(12 \times 11 \mathrm{~cm})$ in the left kidney showing multiple daughter cysts
(Fig. 3c-d). The left kidney's remaining parenchyma did not show avid contrast uptake, confirmed on the DTPA scan. The abdomen was entered through an extended left subcostal incision (Fig. 3h). Before nephrectomy, the sizeable cystic lesion was punctured after isolating it in a field of chlorhexidine soaked mops (Fig. 3e-g). After the aspiration of dirty white fluid and putty material, multiple daughter cysts (Fig. $3 \mathrm{i}-\mathbf{j}$ ) were removed. After decompression, maneuverability improved, and we could proceed with nephrectomy. Pleura adhered to 
Table 1 Summarization of patient characteristics and treatment offered

\begin{tabular}{|c|c|c|c|c|c|c|c|c|c|}
\hline $\mathrm{S} / \mathrm{N}$ & $\begin{array}{l}\text { Socioeconomic } \\
\text { status }\end{array}$ & $\begin{array}{l}\text { Clinical } \\
\text { findings }\end{array}$ & Eosinophilia & $\lg G$ and $\lg M$ & Albendazole & $\begin{array}{l}\text { Scolicidal } \\
\text { agent }\end{array}$ & Imaging & $\begin{array}{l}\text { Therapeutic } \\
\text { intervention }\end{array}$ & Follow-up \\
\hline & & & & & & & $(\mathrm{CECT})$ & & \\
\hline 1 & Low & Flank pain & Present & Not done & $\begin{array}{l}\text { Postopera- } \\
\text { tively }\end{array}$ & Not used & Simple cyst & $\begin{array}{l}\text { Lap cyst } \\
\text { deroofing }\end{array}$ & No recurrence \\
\hline 2 & Low & Flank pain & Present & Negative & $\begin{array}{l}\text { Pre-op and } \\
\text { postopera- } \\
\text { tively }\end{array}$ & $\begin{array}{l}10 \% \\
\text { povidone- } \\
\text { iodine }\end{array}$ & Simple cyst & $\begin{array}{l}\text { Lap pericys- } \\
\text { tectomy }\end{array}$ & No recurrence \\
\hline 3 & Low & Flank pain & Absent & Positive & $\begin{array}{l}\text { Pre-op and } \\
\text { postopera- } \\
\text { tively }\end{array}$ & $\begin{array}{l}10 \% \\
\text { povidone- } \\
\text { iodine }\end{array}$ & $\begin{array}{l}\text { Large cyst } \\
\text { with wall } \\
\text { calcification }\end{array}$ & $\begin{array}{l}\text { Open pericys- } \\
\text { tectomy }\end{array}$ & No recurrence \\
\hline \multirow[t]{2}{*}{4} & Low & $\begin{array}{l}\text { Mass, hydati- } \\
\text { duria and } \\
\text { flank pain }\end{array}$ & Present & Negative & $\begin{array}{l}\text { Pre-op and } \\
\text { postopera- } \\
\text { tively }\end{array}$ & $\begin{array}{l}\text { 10\% } \\
\text { povidone- } \\
\text { iodine }\end{array}$ & $\begin{array}{l}\text { Multilocu- } \\
\text { lated cysts }\end{array}$ & $\begin{array}{l}\text { Open } \\
\text { nephrec- } \\
\text { tomy }\end{array}$ & Doing well \\
\hline & & & & & & & $\begin{array}{l}\text { with no con- } \\
\text { trast uptake } \\
\text { in remnant } \\
\text { paren- } \\
\text { chyma }\end{array}$ & & \\
\hline 5 & Low & $\begin{array}{l}\text { Mass, flank } \\
\text { pain }\end{array}$ & Absent & Negative & $\begin{array}{l}\text { Pre-op and } \\
\text { postopera- } \\
\text { tively }\end{array}$ & $\begin{array}{l}\text { 1.5\% cetrim- } \\
\text { ide-0.15\% } \\
\text { chlorhex- } \\
\text { idine solu- } \\
\text { tion }\end{array}$ & $\begin{array}{l}\text { Multilocu- } \\
\text { lated cyst } \\
\text { with no } \\
\text { contrast } \\
\text { uptake in } \\
\text { remnant } \\
\text { paren- } \\
\text { chyma }\end{array}$ & $\begin{array}{l}\text { Open } \\
\text { nephrec- } \\
\text { tomy }\end{array}$ & pending \\
\hline
\end{tabular}

the cyst wall was excised and repaired, and a chest tube was placed.

\section{Discussion}

The treatment of choice in renal hydatidosis is surgery. Kidney-preserving surgery (removal of hydatid cyst with pericystectomy) is possible in most cases (75\%). Nephrectomy (25\%) is preferable for a non-salvageable kidney [6]. Our first two cases were managed laparoscopically and the remaining three by an open approach due to their large size. Initial cyst aspiration and replacement of cystic liquid with scolicidal agents will sterilize the cyst [7]. The cavity is then opened to remove the endocyst, including the hydatid membrane and the daughter cysts.

Laparoscopic removal of hydatid cyst is rare. There is a fear of cyst rupture and dissemination during dissection, entrapment, and removal of the hydatid cyst during laparoscopy. Utmost care is taken during surgery to prevent spillage and resultant spread. Two cases had a non-functional kidney on imaging and underwent open nephrectomy. Albendazole sterilizes the cyst, decreases anaphylaxis, and decreases tension in the cyst to reduce spillage and recurrence [8]. We ensured preoperative intake of albendazole in all cases except the first, in which we had an impression of a simple renal cyst. Despite not having undertaken antiscolicidal measures and antispillage measures, patient is doing well on follow-up. This could be explained by a decreased parasite load, which was controlled by postoperative albendazole use. In all subsequent cases, adequate antiscolicidal measures were taken with povidone-iodine or cetrimide solution. Other scolicidal solutions used are hypertonic saline, formalin, silver nitrate, and hydrogen peroxide.

In one of the patients, the cyst wall was inseparable from the IVC and duodenum. Here incomplete resection with grossly residual disease was intentionally

(See figure on next page.)

Fig. 2 a CT scan showing multiple cysts in the right kidney with peripheral hypoattenuation (orange arrow) characteristic of a hydatid cyst. b CT scan showing the typical "cyst within a cyst" appearance (orange arrow). c Anti-scolicidal agent (10\% povidone-iodine) soaked mops (white arrow) isolating the hydatid kidney to prevent the spillage. $\mathbf{d}$ Numerous daughter cysts isolated from the excised kidney. e Pus mixed caseous material collected during aspiration ( 2 Litres). $\mathbf{f}$ Scanner view showing the thick fibrotic pericyst (thick black arrow) compressing the native renal parenchyma at the periphery (thin black arrow). The intra-cystic material lies outside and shows the eosinophilic membrane (thin white arrow) corresponding to the ectocyst (hematoxylin and eosin, 20x). $\mathbf{g}$ Higher magnification of the thick fibrotic pericyst (black star) and the compressed native renal parenchyma. A compressed glomerulus is highlighted in the renal parenchyma (black arrow) (hematoxylin and eosin, 40x) 


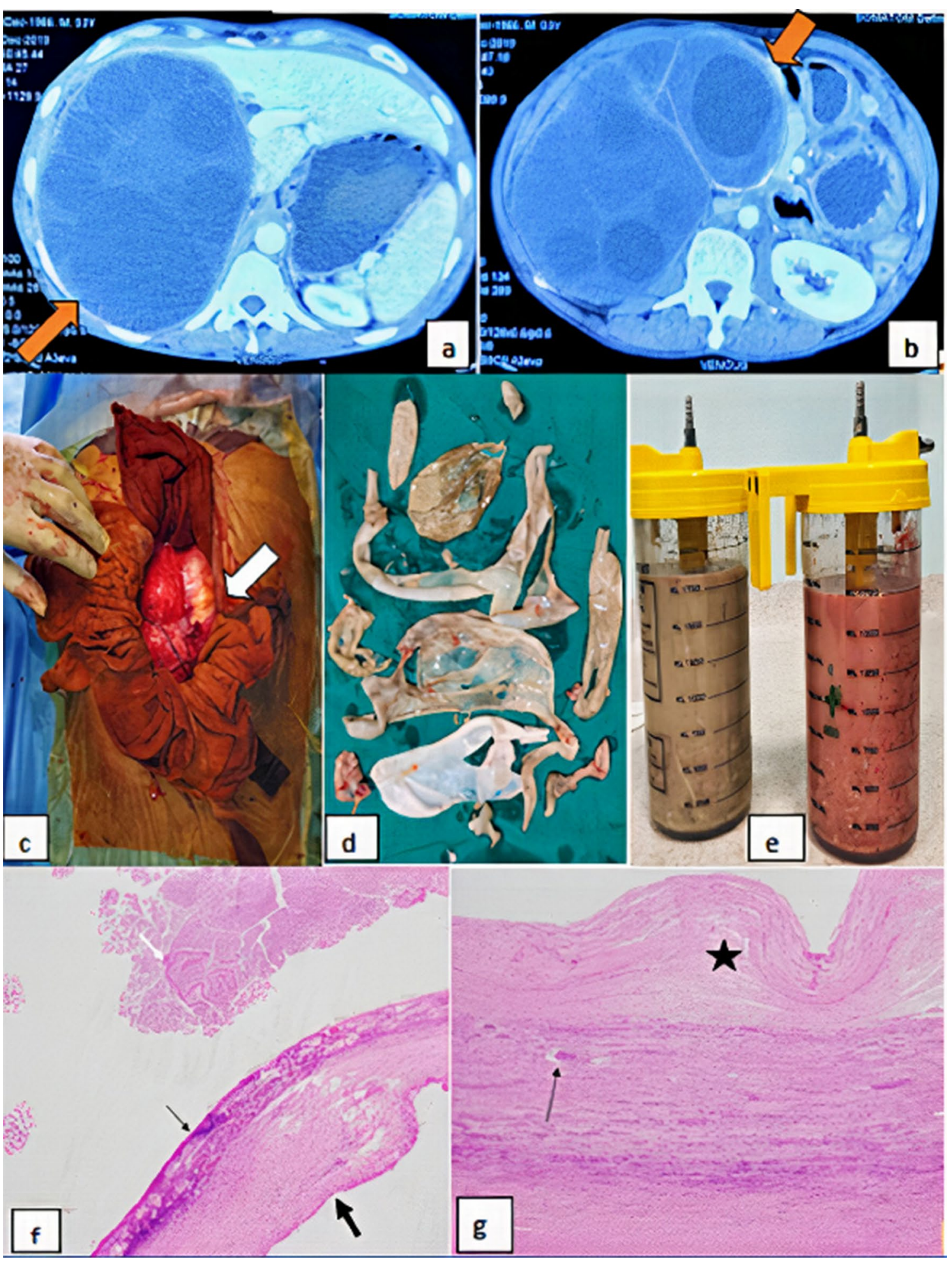

performed to prevent the catastrophe of IVC tear or duodenal injury. This goes to show that voluntary decision of incomplete resection could be taken in individualized cases. In another patient, the cyst wall was inseparably adhered to the visceral pleura, and attempts to separate it led to a pleural injury. Some parts of the pleura had to be 
sacrificed with the cyst wall, but it was repaired primarily, and a chest tube was placed. Thus, completeness of cyst wall excision may depend upon the organs involved.

Eosinophilia occurs in $50 \%$ of cases. In our series, three out of five showed eosinophilia, and all of these were found to contain daughter cysts, which can be considered a sign of active disease [9]. Serology in primary renal hydatidosis is usually negative. We did not perform the echinococcal serology in our first patient, but only one had positive serology out of the subsequent patients. So we could not decipher the role of echinococcal serology in the diagnostic workup of such patients. Serology has high false negative results but can be used as an epidemiological tool to monitor transmission [10]. Recently, counter immunoelectrophoresis against arc-5 has gained wide acceptance as it decreases false positive serology results due to cross-reactivity with other helminth parasites [11]. Degenerating cysts are typically associated with low serum antibody levels.

Dogs and other canids are definitive hosts for the intestinal tapeworm. Gravid proglottids release the eggs that pass in the feces. After ingestion by an intermediate host (sheep and cattle), the egg hatches in the small bowel release the onchospheres that penetrate the intestinal wall and migrate through the circulatory system, especially to the liver and the lungs. Humans become infected by ingesting the embryonated eggs, with resultant release of onchospheres in the intestine and the development of cysts in various organs [12].

It is not clear how the embryo reaches the kidney in cases of primary hydatid disease. However, it possibly passes through the portal system into the liver and the retroperitoneal lymphatics [13]. Hematogenous dissemination may lead to secondary involvement of almost any anatomical location. However, it is mostly unknown how kidneys are selectively involved in isolated renal hydatidosis without the liver or lungs.

The hydatid cyst of the kidney has three layers, i.e., pericyst (modified renal tissue), ectocyst (external laminated membrane), and endocyst (internal germinal membrane). In an open or communicating cyst, the layers rupture, resulting in free communication with the calyces and pelvis.

Echinococcal renal cysts resemble a slow-growing renal tumor, distorting the collecting system, and putting pressure on the renal parenchyma, leading to atrophy and secondary arterial hypertension. Renal hydatid cyst may present with flank pain, haematuria, ureteropelvic junction obstruction, and chronic renal failure [14]. Cystic rupture into the collecting system causes hydatiduria and acute renal colic, which is pathognomonic. Daughter cysts in urine lack the pericyst contributed by the host.

Ultrasonography (US) may show daughter cysts and hydatid sand, which shift on changing the posture of the patient. Radiological imaging with $\mathrm{CT}$ and magnetic resonance imaging (MRI) remain the mainstay of diagnosis. CT scan has an accuracy of $98 \%$ in demonstrating hydatid cysts. Type 1 cysts correspond to the initial development stage and appear unilocular without any internal architecture. Type 2 cysts are at an intermediate stage of parasite development, containing multiple daughter cysts, and Type 3 cysts are completely calcified, representing the dead parasite [15]. The usual description is an expansile, hypoattenuating tumor with well-defined walls and the presence of daughter cysts within the parent cyst. The cyst's central region has an attenuation of 30-35 HU due to the unique high fluid content of the mass, in contrast to the much lower attenuation of the fluid in the surrounding cysts $(5-15 \mathrm{HU})$, giving a rosettelike appearance [16]. However, this is non- confirmatory as seen in one of our patients, where it appeared as a simple cyst with standard HU but proved to be a hydatid cyst.

The danger of rupture or spillage of the highly antigenic contents precludes aspiration of hydatid cyst [17]. It is difficult to predict which patient may suffer from anaphylactic shock during the surgical treatment. Levels of interleukin-4 and cyst size may be independently associated with perioperative anaphylacyic shock [18].

The main limitation of our case series is that it is a single-center experience with five cases. The time duration of preoperative albendazole was not standardized in all cases. Echinococcal serology was not done in one patient.

\section{Conclusions}

Correct diagnosis is imperative to start preoperative albendazole and take measures to prevent spillage. Complications like a severe allergic reaction and parasitic dissemination are rare with the use of scolicidal agents. On the contrary, we found no complications of anaphylaxis

(See figure on next page.)

Fig. 3 a Lump seen involving the left hypochondrium, left lumbar and umbilical region of the abdomen, crossing the midline. $\mathbf{b}$ Abdominal lump visible as a significant swelling from the side view. c CT scan showing multiloculated nature (white arrow) of hydatid cyst. $\mathbf{d}$ CT scan showing the large cyst compressing the rest of the parenchyma with no significant contrast uptake, e Huge hydatid cyst of the left kidney brought into the field of operation. f Antiscolicidal measures being taken during aspiration with chlorhexidine soaked mops (white arrow). g Daughter cysts being cleared from a large cyst (white arrow) to facilitate nephrectomy. $\mathbf{h}$ Left subcostal scar mark in the postoperative period. i-j Multiple daughter cysts found within the resected kidney 


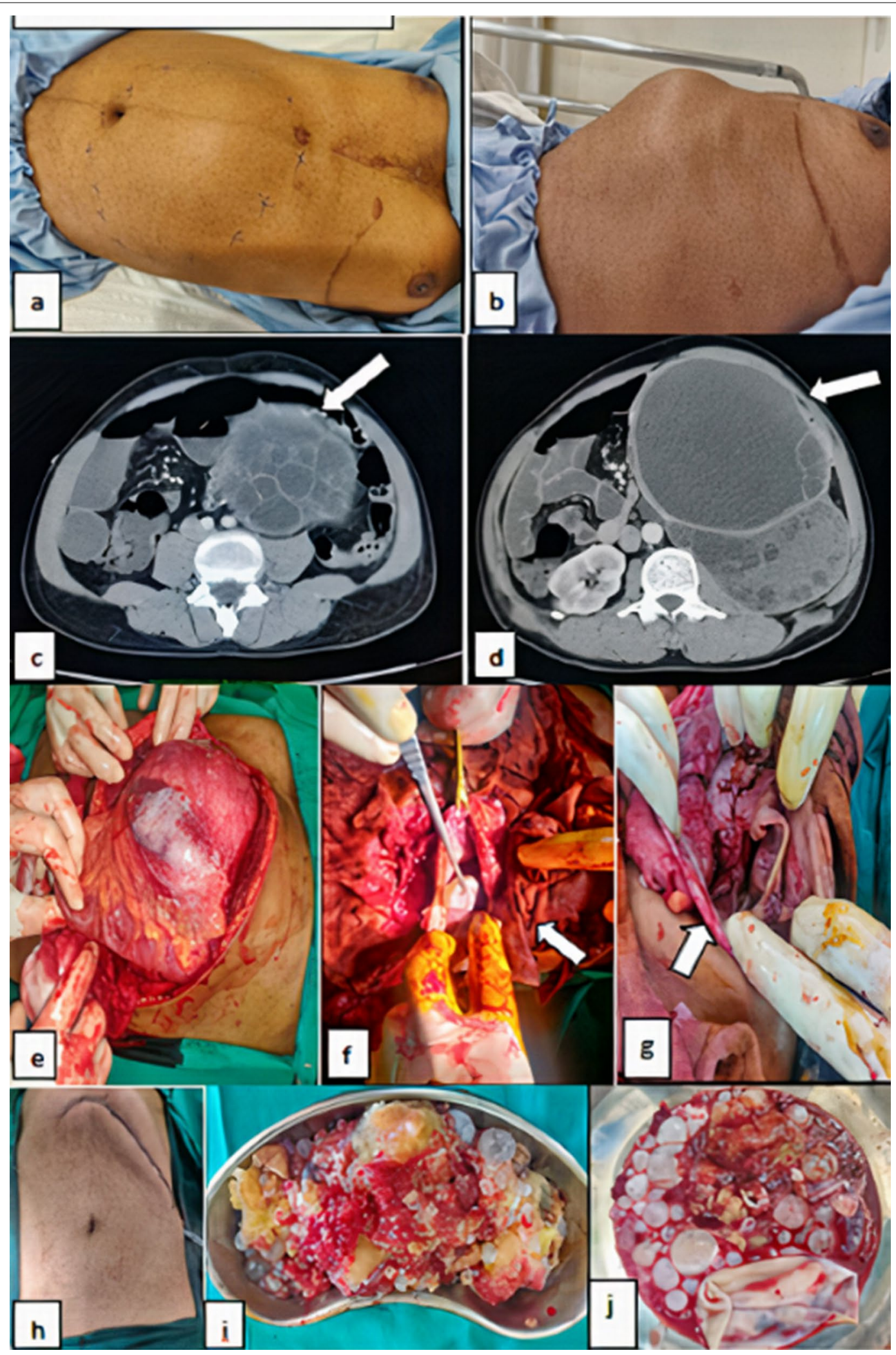


or systemic disease in our first case in which no such precautions were taken due to a mistaken diagnosis of simple renal cyst. While we found eosinophilia in $60 \%$ of the patients, more studies are required to investigate the role of eosinophilia in predicting disease severity and its infectivity. Echinococcal serology did not correlate with active disease. Hypoattenuation in the periphery of the multiloculated cyst with hyper attenuation in the center may indicate a hydatid cyst's diagnosis. However, as we see, one rule does not fit all, and a multimodal approach, including history, serology, hematology, imaging, and histopathology, is suggested for the best management. The aim should be to preserve the renal function and opt for nephrectomy only if a non-functional kidney is present. It appears best to individualize the approach on a case to case basis.

\section{Abbreviations}

CT: Computed tomography; OPD: Outpatient department; CECT: Contrastenhanced computed tomography; Ig: Immunoglobulin; IVC: Inferior vena cava; DTPA: Diethylene tetra-amine penta-acetic acid; US: Ultrasound; HU: Hounsfield units.

\section{Acknowledgements \\ Not applicable.}

\section{Authors' contributions}

AM and SM (2) were involved in drafting the manuscript. MD and PN were involved in literature review and proofreading of the manuscript. PM and SM (5) were responsible for histopathological diagnosis, description of microscopic findings, and provision of the microphotographs. All the authors have read and approved the manuscript.

\section{Funding}

None.

\section{Availability of data and materials}

All data generated or analyzed during this study are included in this published article.

\section{Declarations}

\section{Ethics approval and consent to participate}

The authors state that written informed consent was obtained from the patient for collection and publication of case details and photos. Institutional Ethics Committee, All India Institute of Medical Sciences, AlIMS Bhubaneswar, exempted it from review, reference number: T/IM-NF/Urology/21/18.

\section{Consent for publication}

Written consent to publish this information has been obtained from the study participants.
Received: 11 November 2020 Accepted: 14 March 2021

Published online: 27 June 2021

\section{References}

1. Reza HAM, Rreza G, Nastaran B, Mousa M (2019) Renal hydatid cyst; a rare infectious disease. Oxf Med Case Reports 29(3):omz011

2. Alqasem S, Alqurmalah S, Alsahn B, Ahmed A, Moazin M, Alfakhri A (2020) Unilocular huge renal hydatid cyst mimicking simple cyst: A rare case report. Urol Case Rep 31:101165

3. Singh V, Devana SK, Gorsi U, Bal A (2019) Isolated renal hydatid cyst masquerading as cystic renal tumor. Urology 133:e11-e12

4. Mehra K, Shiv N, Biswas M, Yadav MS, Panwar H (2020) A rare case of renal pelvic hydatid cyst masquerading as renal calculi. J Endourol Case Rep 6(4):421-424

5. Cappello E, Cacopardo B, Caltabiano E et al (2013) Epidemiology and clinical features of cystic hydatidosis in Western Sicily: a ten-year review. World J Gastroenterol 19(48):9351-9358

6. Kumar SA, Shetty A, Vijaya C, Geethamani V (2013) Isolated primary renal echinococcosis: a rare entity. Int Urol Nephrol 45(3):613-616

7. Horchani A, Nouira Y, Kbaier I, Attyaoui F, Zribi AS (2000) Hydatid cyst of the kidney. A report of 147 controlled cases. Eur Urol 38(4):461-467

8. Monga R, Naraya S, Kundu AK (2008) Primary hydatid cyst of kidney and ureter with gross hydatiduria. A case report and evaluation of radiological features. Indian J Urol 24:116-117

9. Chaouch MA, Dougaz MW, Cherni S et al (2019) Daughter cyst sign in liver hydatid cyst. J Parasit Dis 43:737-738

10. Yang YR, Craig PS, Vuitton DA, Williams GM, Sun T, Liu TX et al (2008) Serological prevalence of echinococcosis and risk factors for infection among children in rural communities of Southern Ningxia, China. Trop Med Int Health 13:1086-1094

11. Babba H, Messedi A, Masmoudi S et al (1994) Diagnosis of human hydatidosis: comparison between imagery and six serologic techniques. Am J Trop Med Hyg 50:64

12. Moro P, Schantz PM (2009) Echinococcosis: a review. Int J Infect Dis 13(2):125-133

13. Pedrosa I, Saíz A, Arrazola J, Ferreirós J, Pedrosa CS (2000) Hydatid disease: radiologic and pathologic features and complications. Radiographics 20(3):795-817

14. Yaycioglu O, Ulusan S, Gul U, Guvel S (2006) Isolated renal hydatid disease causing ureteropelvic junction obstruction and massive destruction of kidney parenchyma. Urology 67:1290.e15-17

15. Ishimitsu DN, Saouaf R, Kallman C, Balzer BL (2010) Best cases from the AFIP: renal hydatid disease. Radiographics 30(2):334-337

16. Volders WK, Gelin G, Stessens RC (2001) Hydatid cyst of the kidney: Radiologic-pathologic correlation. Radiographics 21:S255-S260

17. Akhan O, Ustunsoz B, Somuncu I, Ozmen M, Oner A, Alemdaroqlu A et al (1998) Percutaneous renal hydatid cyst treatment: long-term results. Abdom Imag 23:209-213

18. Ye J, Zhang Q, Xuan Y, Chen S, Ma L, Zhang Y et al (2016) Factors associated with echinococcosis-induced perioperative anaphylactic shock. Korean J Parasitol 54(6):769-775

\section{Publisher's Note}

Springer Nature remains neutral with regard to jurisdictional claims in published maps and institutional affiliations.

\section{Competing interests}

The authors have no competing interests to declare. 